Document downloaded from:

http://hdl.handle.net/10251/159205

This paper must be cited as:

Guardiola, C.; Pla Moreno, B.; Bares-Moreno, P.; Stefanopoulou, A. (2019). Cylinder charge composition observation based on in-cylinder pressure measurement. Measurement. 131:559-568. https://doi.org/10.1016/j.measurement.2018.08.024

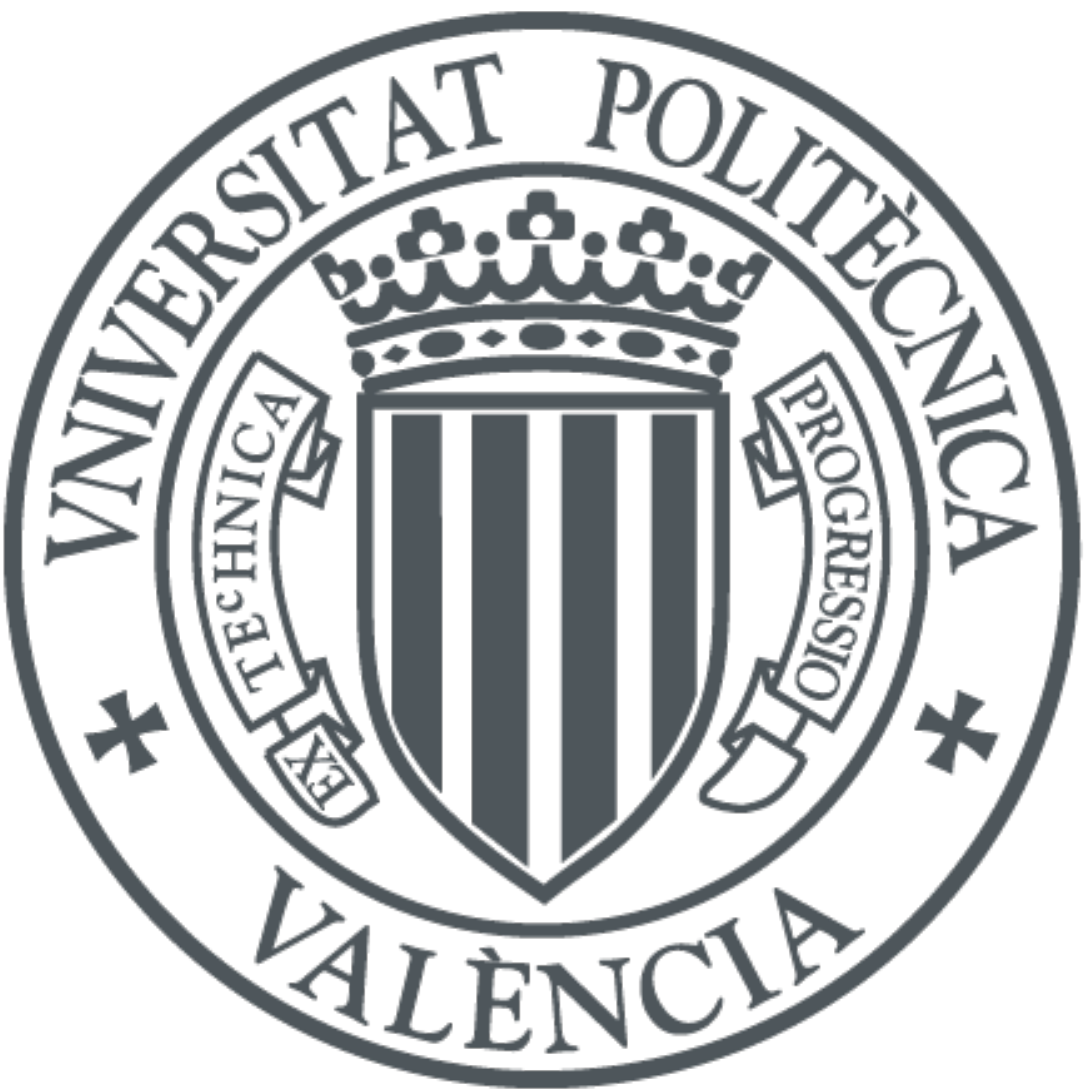

The final publication is available at

https://doi.org/10.1016/j.measurement.2018.08.024

Copyright Elsevier

Additional Information 


\title{
Cylinder charge composition observation based on in-cylinder pressure measurement
}

\begin{abstract}
Accurate cylinder charge and composition estimation is crucial for proper combustion control, however, current sensors and models show different issues for transient estimation. The work presented in this paper combines a novel technique for trapped mass estimation, which relies on the in-cylinder pressure resonance, with on-board engine sensors by taking into account the sensors and the intake manifold dynamics with a closed-loop observer.

The resonance method provides a measurement of trapped mass with one cycle resolution. This measurement feeds a Kalman filter to improve the transient and steady response of the intake charge and composition estimation. The observer was validated in a four stroke heavy-duty engine, showing fast transient capabilities and an adequate steady-state accuracy.
\end{abstract}

Key words: , resonance, sensor fusion, Kalman filter, observer, trapped mass, internal combustion engines, trapped mass, in-cylinder pressure

\section{Introduction}

The estimation and control of the cylinder charge and its composition is already crucial in conventional combustion modes: the composition in SI engines must be maintained in stoichiometric conditions in order to properly operate 5 the three way catalyst (TWC) $[1,2,3]$, and the soot- $\mathrm{NO}_{x}$ trade-off in CI engines is highly affected by external gas recirculation (EGR) $[4,5,6]$. In addition, an accurate intake composition estimation in engines working with low temperature combustion concepts will be necessary not only for emissions control, but also for combustion stability [7, 8, 9]. Such accurate and fast composition estimation is a big challenge for the current set of sensors included in commercial electronic contol units (ECUs). The usual set of sensors includes a combination of air mass flow, pressure, and temperature sensor at the intake and a lambda sensor at the exhaust.

15 Hot film anemometers, usually installed on-board to measure the air mass flow at the intake $[10,11,12]$, show a non-linear time response[13, 14, 15] 
that varies in the range of $30-50 \mathrm{~ms}$, and are subjected to severe ageing due to the accumulation of dust on the sensing element, which causes a bias that can reach $20 \%$ of the measured value $[16,17,18]$. In addition, they are usually placed at the beginning of the intake line, far away from the cylinder port, thus limiting any cycle-to-cycle mass flow determination and being significantly affected by intake system filling dynamics.

The injected fuel mass is estimated on-board through the differences in pressure at the injector and the energizing time, however, common rail systems have cylinder-to-cylinder dispersion due to minor errors in hole diameter, unavoidable owing to manufacturing variation and to the accumulation of deposits $[19,20]$ and the use of multi-injection strategies in common rail systems also increases the uncertainties in the final measurement due to pressure 30 waves in the injection line [21,22]. Universal exhaust oxygen sensors UEGO ( $\lambda$ sensors) $[23,24]$ or new on-board $\mathrm{NO}_{x}$ sensors $[25,26,27]$ permit a linear resolution of the fuel to air ratio over a wide range. Both sensors are also affected by ageing, e.g. Schilling [28] reported a $5 \%$ error at $\lambda<0.8$ and a $8.8 \%$ at $\lambda>1.7$, when ageing UEGO sensors during 3000 working hours.

The estimation of exhaust Gas Recirculation (EGR) is one of the most challenging aspects. Common on-board flow rate meters cannot be used at the extreme exhaust conditions, namely temperature and particles concentration $[29,30]$, and the EGR on-board estimation is usually performed by substracting the air mass flow to the overall trapped mass estimated by the speed density method, which relies in the volumetric efficiency estimation and a temperature and pressure measurement at the intake manifold [31, 32].

Traditionally, the volumetric efficiency is calibrated as a function of the engine speed $n$ and intake manifold pressure $p_{\text {int }}$ with a 2D table [33]. However, variable valve timing (VVT) strategies for intake charge control increase the degrees of freedom for the volumetric efficiency estimation [34, 35], and it cannot be stored as a simple 2D table [36]. Some solutions for modelling the volumetric efficiency can be found in $[37,38,39]$ by using neural networks, or in $[40,41]$ by using physical-based models for $\eta_{v}$ in engines with VVT. Although the time response of speed-density approaches is sufficient, variations in the operating conditions, such as wall heat transfer or fluid friction losses, can lead to significant model errors in transient operation [42, 43].

Regarding the EGR estimation in test benches, $\mathrm{CO}_{2}$ balance is the most commonly used technique $[44,45,46]$. Nevertheless, the transient response of this measurement technique highly depends on the gas analyser system response and on the intake and exhaust manifold dynamics, leading to significant errors when transients are considered [47]. Furthermore, several authors have pointed 
out the relevance of the probe location in high-pressure EGR loops: because of incomplete mixing, high-pressure loops create a notable cylinder-to-cylinder dispersion, which may lead to a bias in the determined EGR rate [48, 49, 50].

Some authors suggest using the orifice principle to model the mass flow rate at the EGR valve $[51,52,53]$. However, this technique requires a detailed knowledge of the valve flow process, i.e. the instantaneous effective area and the conditions at the inlet and outlet of the valves, which may be not available in on-board applications or might lead to significant errors when the sensor measurements are not representative of the conditions at the surroundings of the valve.

70 Recent developments in in-cylinder pressure sensors have lowered the cost of such sensor while the number of application are justifying its commercial application. A new methodology proposes the derivation of the trapped mass through the analysis of the resonant frequency of the in-cylinder pressure oscillations. The method was recently applied to DI and HCCI engines $[54,55,56]$, 75 and some applications, i.e. NOx and residual gas fraction estimation, have been already explored $[57,58]$.

In this scenario, it may be expected that new engines combine several of the aforementioned sensors, thus processing a variety of information sources for the cylinder charge estimation. In such data-rich environment, advanced techniques may be used for improving the estimation of the air charge and intake composition. Closed-loop observers are a tool for combining information coming from sensors placed at various locations to determine the charge and the composition at the intake. The dynamics at the intake and exhaust process control volume with the mass and energy conservation equations, by assuming no wall heat transfer and perfect gas mixture composition [59,60,61]. This is the case of Leroy et al. [62] where the manifold air mass flow $m_{\text {air }}$ is considered as an input, the intake pressure $p_{\text {int }}$ is the system state, and unknown parameters can be included in the state equations. Similar examples of Luenberg-like observers can be found in $[63,64]$ for air-charge estimation in SI engines, in $[65,52,66]$ for EGR estimation by using isothermal intake model dynamics and in $[51,67,68]$ by using the transport equations at the intake for the burnt gases concentration.

Kalman filters (KF) are a concrete type of closed-loop observers where the observer gains are continuously adapted to improve the convergence and accuracy of the observer [69, 70]. Several examples can be found in literature 
for automotive applications: in [71], an extended Kalman filter is proposed for

\section{Experimental facility}

Experimental tests were carried out in a heavy-duty engine equipped with port fuel gasoline injection and diesel direct injection. The engine can work with conventional diesel combustion by deactivating the port fuel injection, or using both injections for performing RCCI or PPCI dual fuel combustions. The main characteristics of the engine are collected in Table 1.

Table 1

Main engine characteristics

\begin{tabular}{lcc} 
Field & Units & Value \\
\hline Cycle & {$[-]$} & 4 -stroke \\
Cylinders & {$[-]$} & 6 \\
Combustion type & {$[-]$} & CI-RCCI \\
Unitary displacement & {$[\mathrm{cc}]$} & 1300 \\
Bore & {$[\mathrm{mm}]$} & 110 \\
Compression ratio & {$[-]$} & $12.2: 1$
\end{tabular}

A low-pressure EGR loop was used to guarantee a good mixing with a better efficiency. However, a high-pressure EGR loop was also used to ensure 
sufficient EGR when the exhaust and intake conditions do not allow the LPEGR to provide the engine with the required residual gases. The in-cylinder pressure was sensed by Kistler $6125 \mathrm{C}$ pressure sensors with a resolution of 5 samples/CAD. The exhaust gases where analysed with an Horiba MexaONE-D1-EGR. A complete scheme of the experimental test bench is shown in Figure 1.

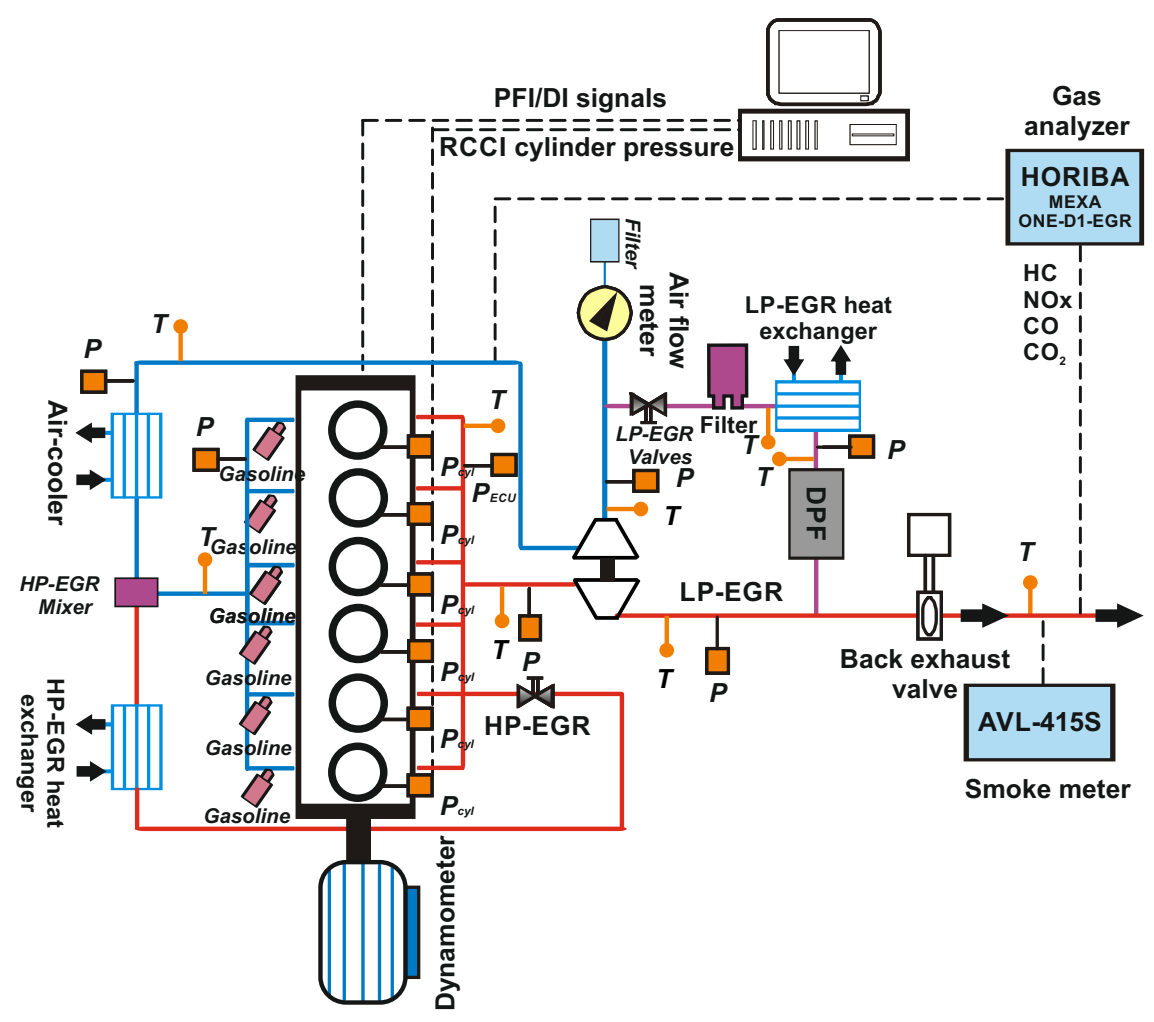

Fig. 1. Experimental set-up

Two type of transient tests were performed to calibrate and validate the models and the observer performance:

- Mass flow variations: The VGT was controlled to modify the intake charge at various engine speed conditions, namely 1000, 1200, 1500 and $1800 \mathrm{rpm}$. At each engine speed a slow increase of the VGT running from the minimum VGT action (limited by misfire occurrences) to the maximum VGT position (fully closed) was used for calibration and steady validation purposes. Afterwards, fast steps were performed ending at the same initial VGT position to analyse the dynamic response of the mass flows. The EGR valve was closed in order to reduce the number of uncertainties. Figure 2 shows the evolution of the intake pressure and the engine speed during such tests.

- EGR steps: Four steps were performed at $1200 \mathrm{rpm}$ to analyse the dynamic 
response of the system. The LP-EGR valve, and the HP-EGR valve, were sharply controlled from the minimum to its maximum value to see its effect at the intake charge and composition. The aforementioned steps (HP-EGR valve, LP-EGR valve) were executed at $25 \%$ and $75 \%$ load conditions.
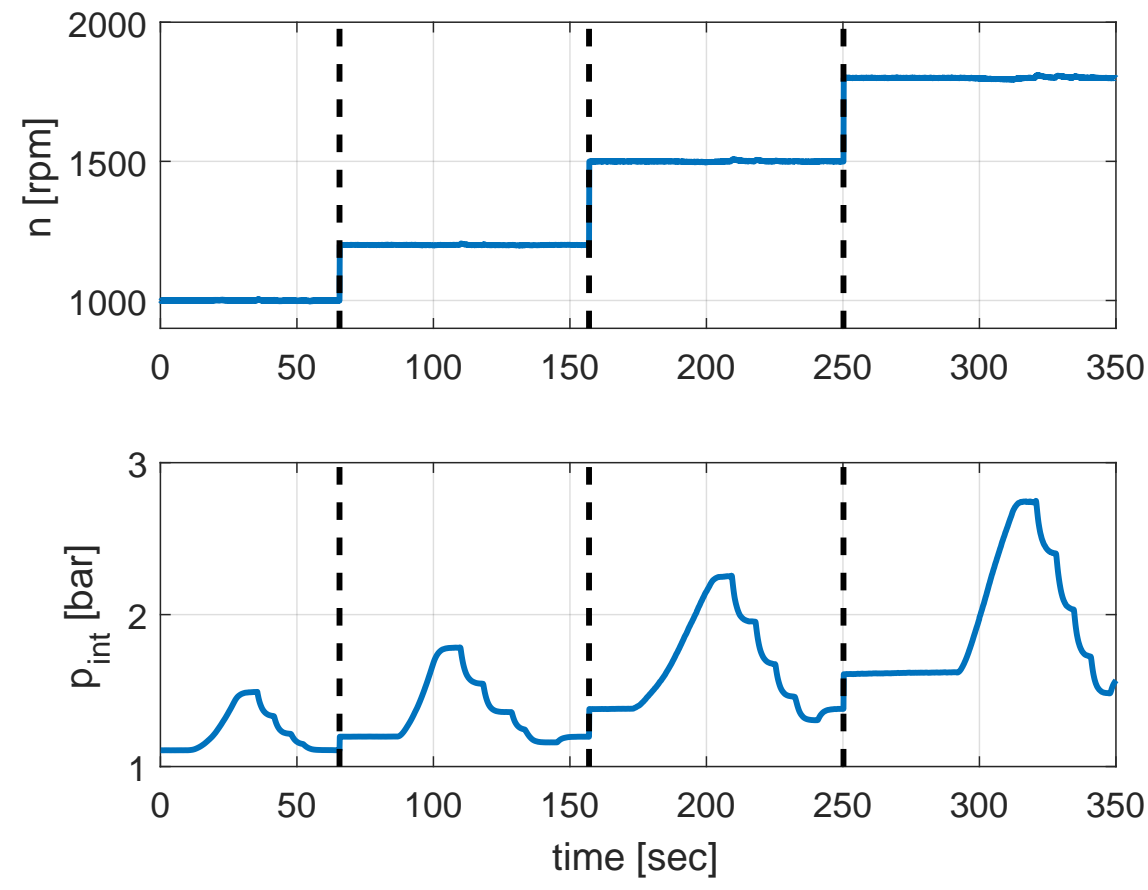

Fig. 2. Calibration tests with EGR valve closed

\section{Model and observer description}

The goal of the paper is to exploit the full potential of a sensor rich environment. The proposed observer makes use of several sensors: a piezo-resistive pressure sensor and a lambda sensor at the exhaust, an air mass flow meter, a piezo-resistive pressure sensor, and a temperature thermocouple at the intake, and a virtual sensor of the trapped mass, derived from the in-cylinder pressure sensor. Figure 3 shows an scheme of the main mass flows, where the sensors used have been marked with a filled black circle.

The total trapped mass $\left(m_{c y l}\right)$ has been inferred from the in-cylinder pressure resonance, harnessing the relation between the frequency of the first resonant mode $\left(f_{\text {res }}\right)$ and the trapped mass $[54,55]$, which is described by: 


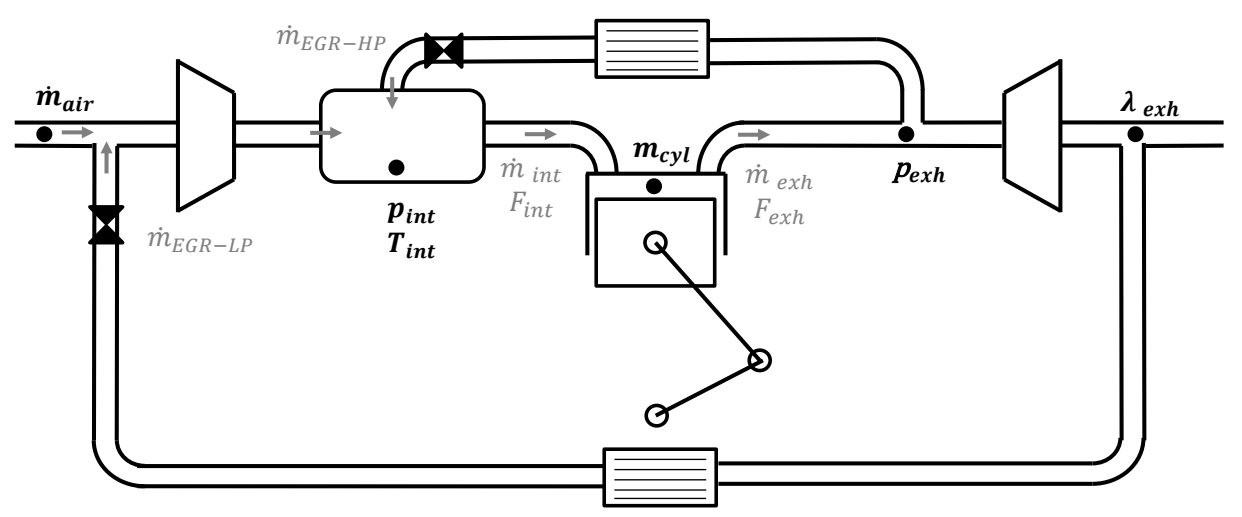

Fig. 3. Scheme of the sensors used and the main mass flows: Mass flows have been represented by $\dot{m}$ when are measured or expressed in $\mathrm{kg} / \mathrm{h}$, nevertheless, they can be also used in $\mathrm{kg}$ per stroke (represented by $m$ ) using the engine speed for the conversion

$$
m_{c y l}=\frac{B_{1,0}^{2} \gamma p V}{\left(f_{r e s} \pi D\right)^{2}}
$$

where $\gamma$ is the heat capacities ratio, $D$ the bore of the cylinder head, $B_{1,0}$ the bessel constant that characterizes the first resonant mode, $p$ the in-cylinder pressure, and $V$ the instantaneous volume of the combustion chamber, which can be derived from the crank angle evolution if the crank, the rod and the bore lengths are known. A specific transformation developed by the authors in [56], which consists on a variation of the Fourier transform, has been used to analyse these frequency varying harmonics.

The intake charge $\left(m_{\text {int }}\right)$ is commonly represented by a volumetric efficiency through the speed density method, following:

$$
m_{\text {int }}=\eta_{v} \frac{p_{\text {int }} V_{\text {dis }}}{R T_{\text {int }}}
$$

where $\eta_{v}$ is the volumetric efficiency, $p_{\text {int }}$ and $T_{i n t}$ are the intake pressure and temperature, respectively, $V_{\text {dis }}$ the displaced volume, and $R$ the constant of the gases, which might be assumed $287 \mathrm{~J} / \mathrm{KgK}$ (air) for simplicity. The volumetric efficiency is commonly bounded between 0.8 and 0.95 and can be tabbed as a function of the intake pressure and the engine speed.

To harness the total trapped mass given by the resonance method in order to update the volumetric efficiency, an estimation of the injected fuel $\left(m_{f u e l}\right)$ and the residual gasses trapped $\left(m_{\text {res }}\right)$ is required, following: 


$$
m_{\text {cyl }}=m_{\text {res }}+m_{\text {fuel }}+m_{\text {int }}=\frac{m_{\text {fuel }}+m_{\text {int }}}{1-R G F}
$$

The Residual Gas Fraction (RGF) was modelled such as suggested by Yun and Mirsky in [74] by assuming a polytropic expansion at the exhaust valve between the exhaust valve opening (EVO) and the exhaust valve closing (EVC), following:

$$
R G F=\frac{m_{r e s}}{m_{c y l}}=\left(\frac{p_{E V C}}{p_{E V O}}\right)^{\frac{1}{\gamma}}\left(\frac{V_{E V C}}{V_{E V O}}\right)
$$

While the fuel was estimated through a look-up table model, that estimates the injected fuel mass from the energizing time and the pressure ratio at the injector. The pressure ratio in the diesel injection is characterized by the rail pressure, as the rail pressure is much higher than the cylinder pressure, while in the gasoline injection the intake pressure is the main variable, as the injection pressure was maintained constant at 5.5 bars.

The intake charge, composed from fresh air $\left(m_{\text {air }}\right)$ and external gas recirculation $\left(m_{E G R}\right)$, is affected by the intake manifold dynamics, which is characterized by the accumulation of such mass flows. The intake manifold dynamics, is described by the mass and energy conservation equations, and can be simplified to the so named isothermal model:

$$
\dot{p}_{i n t}=\frac{R T_{i n t}}{V_{m}}\left(m_{\text {air }}+m_{E G R}-m_{\text {int }}\right)
$$

where $V_{m}$ is the intake manifold volume.

The isothermal model is commonly used in automotive applications where the EGR temperature is close to the intake air temperature, which can be assumed in EGR configurations equipped with intercooler.

The EGR mass $\left(\dot{m}_{E G R}\right)$ was inferred from the compressible flow orifice equation, such as suggested in [52], following:

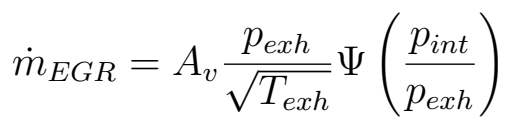


where $A_{v}$ is the effective area, $p_{\text {exh }}$ and $T_{\text {exh }}$ are the pressure and temperature at the inlet side (exhaust manifold), $p_{\text {int }}$ is the pressure at the outlet (inlet manifold), and $\Psi$ is a function of the pressure ratio defined by:

$$
\Psi\left(\frac{p_{\text {int }}}{p_{\text {exh }}}\right)=\left\{\begin{array}{cl}
\sqrt{\gamma\left(\frac{2}{\gamma+1}\right)^{\frac{\gamma+1}{\gamma-1}}} & \text { if } p_{\text {exh }}<p_{\text {int }}\left(\frac{2}{\gamma+1}\right)^{\frac{\gamma}{\gamma-1}} \\
\left(\frac{p_{\text {int }}}{p_{\text {exh }}}\right)^{\frac{1}{\gamma}} \sqrt{\frac{2 \gamma}{\gamma-1}\left[1-\left(\frac{p_{\text {int }}}{p_{\text {exh }}}\right)^{\frac{\gamma-1}{\gamma}}\right]} & \text { if } p_{\text {exh }} \geq p_{\text {int }}\left(\frac{2}{\gamma+1}\right)^{\frac{\gamma}{\gamma-1}}
\end{array}\right.
$$

the exhaust pressure was measured by a pressure sensor loacted at the exhaust, in commercial applications it is normally measured combining the intake pressure sensor with a gauge differential pressure sensor. The exhaust temperature was obtained by assuming a polytropic evolution at the exhaust valve process, such as suggested in [74].

Once the mass flows are known, the oxygen concentration at the exhaust manifold can be computed by subtracting the oxygen burnt by the fuel to the oxygen concentration at the intake, through:

$$
F_{\text {exh }}=\frac{F_{\text {int }} m_{\text {int }}-14.6 F_{\text {air }} m_{\text {fuel }}}{m_{\text {fuel }}+m_{\text {int }}}
$$

where $F$ represents the concentration of oxygen $\left(F_{\text {air }}=21 \%\right)$, and 14.6 is the stoichiometric air to fuel ratio (for diesel $\approx 14.6$, for Gasoline $\approx 14.7$ ).

The oxygen concentration at the exhaust can be also derived from the lambda sensor, through:

$$
F_{\text {exh }}=F_{\text {air }}\left(1-\frac{1}{\lambda}\right)
$$

While the evolution of the oxygen concentration at the intake can be modelled by considering the intake manifold dynamics, through:

$$
\dot{F}_{\text {int }}=\frac{R T_{\text {int }}}{p_{\text {int }} V_{m}}\left[m_{\text {air }}\left(F_{\text {air }}-F_{\text {int }}\right)+m_{E G R}\left(F_{E G R}-F_{\text {int }}\right)\right]
$$

where the EGR oxygen concentration $\left(F_{E G R}\right)$ can be approximated by the exhaust oxygen concentration $\left.F_{\text {exh }}\right)$ if exhaust manifold and EGR system dynamics are neglected. 
The cylinder oxygen concentration can be estimated by combining the intake gases with the residual gases, such as:

$$
F_{c y l}=F_{\text {int }}(1-R G F)+F_{\text {exh }} R G F
$$

The aforementioned equations can be combined to provide an estimation of

the intake and exhaust composition evolution, as well as an observation of each mass flow. At this step, three important simplifications have been taken:

- Instantaneous measurement of sensors: Pressure sensors can be considered instantaneous as the time-response of these sensors is much lower than the duration of a cycle. The temperature was measured by a thermocouple which is sufficient to capture the dynamics of the intake manifold temperature, while the time response of the hot-film anemometer and the UEGO sensors are normally bounded bellow $100 \mathrm{~ms}$, which is the time of one cycle at $1200 \mathrm{rpm}$.

In order to reduce the complexity of the model, all the aforementioned sensors have been considered instantaneous for a cycle-by-cycle period estimation. But if a NTC sensor was used for measuring the intake temperature or the lambda output was obtained from a smart $\mathrm{NO}_{x}$ sensor, sensor dynamics are to be considered. A simple solution of doing so is a first order system, which might be included as:

$$
x_{S}^{k+1}=\left(a_{S}\right) x_{S}^{k}+\left(1-a_{S}\right) x^{k}
$$

where $x$ represents a given measurement, $x_{S}$ represents the measurement from the sensor, and $a_{S}$ a constant characterizing the time response of the sensor.

- An isothermal intake manifold: The temperature variations at the intake manifold have been neglected. This assumption can be taken when the recirculated EGR is equipped with an intercooler which lowers the EGR temperature close to the intake temperature, so even in sharp VGT or EGR steps the intake temperature does not change abruptly and it is mainly a function of the overall engine temperature.

Figure 4 shows a VGT and a HP-EGR step at high load and $1200 \mathrm{rpm}$ : the intake temperature has been plotted with a black line at the left yaxis while the intake pressure or the EGR have been represented by a grey line in the right y-axis. It can be noticed that the variations at the intake temperature are negligible at the VGT step and small (bellow $4 \%$ )at the HP-EGR step, but in both cases the variations last few seconds and can be 
captured by the thermocouple whose time response is characterized around 3 second by the manufacturer.

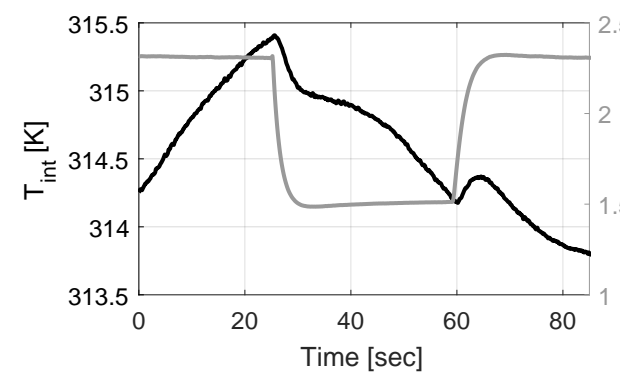

(a) VGT step

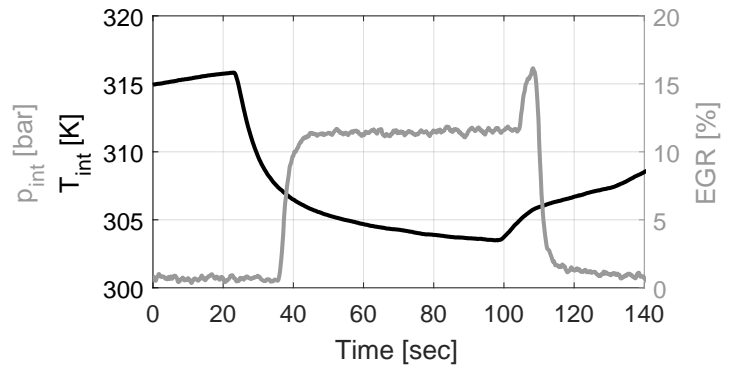

(b) HP-EGR step

Fig. 4. VGT and EGR steps at $1200 \mathrm{rpm}$ and $75 \%$ load

- EGR oxygen concentration: As previously mentioned, the EGR concentration is approximated to the exhaust concentration $\left(F_{E G R} \approx F_{\text {exh }}\right)$, thus, neglecting the transport delay at the EGR line. This is specially critical in LP-EGR conditions, where the transport delay can reach more than 1 second.

Although that approximation does not affect the steady result, it precludes the use of the lambda sensor information for obtaining a good dynamic measurement of the injected fuel mass when high quantities of LPEGR are considered. It must be remarked that only the dynamic measurement of the injected fuel mass would be affected, as the other mass quantities are governed by equation (5).

\section{Observer design}

A Kalman filter was designed to identify model and sensor errors by combining the measurements and the dynamics at the intake manifold. The main challenges of the observer are:

- A precise estimation of the EGR, taking into account that the estimation provided by equation (6) is not accurate given the uncertainties around the valve, as well as the effect of pulsating flow $[75,76]$.

- A correction of the volumetric efficiency to deal with off-design conditions not predicted by the 2D table.

- A continuous calibration of the air mass flow anemometer by analysing if a bias is produced in the sensor. 
- And an adaptation of the injected fuel quantity to correct common errors of the injector model.

To cope with those objectives, four states have been created, namely a bias at the volumetric efficiency, a bias at the injected fuel, a bias at the sensed air mass flow, and the EGR mass. Furthermore, to combine sensors placed at various locations, the manifold dynamics described by (5) and (10) and the relation between the intake oxygen concentration and the exhaust oxygen concentratino given by (8) are also included, leading to the following set:

$$
\begin{aligned}
& \theta_{\eta}^{k+1}=\theta_{\eta}^{k} \\
& \theta_{f}^{k+1}=\theta_{f}^{k} \\
& \theta_{\text {air }}^{k+1}=\theta_{\text {air }}^{k} \\
& m_{E G R}^{k+1}=m_{E G R}^{k} \\
& p_{\text {int }}^{k+1}=p_{\text {int }}^{k}+\frac{R T_{i n t}^{k}}{V_{m}}\left(m_{\text {air }}^{k}+\theta_{\text {air }}^{k}+m_{E G R}^{k}-\left(\eta_{O L}^{k}+\theta_{\eta}^{k}\right) \frac{p_{i n t}^{k} V_{\text {dis }}}{R T_{i n t}^{k}}\right) \\
& F_{i n t}^{k+1}=F_{i n t}^{k}+\frac{R T_{i n t}^{k}}{p_{i n t}^{k} V_{m}}\left[\left(m_{\text {air }}^{k}+\theta_{\text {air }}^{k}\right)\left(F_{\text {air }}-F_{\text {int }}^{k}\right)+m_{E G R}^{k}\left(F_{\text {exh }}^{k}-F_{i n d}^{k}(1)\right)^{8}\right) \\
& F_{e x h}^{k+1}=\frac{F_{i n t}^{k}\left(\eta_{O L}^{k}+\theta_{\eta}^{k}\right) \frac{p_{i n t}^{k} V_{d i s}}{R T_{i n t}^{k}}-14.6 F_{\text {air }}\left(m_{f u e l, O L}^{k}+\theta_{f}^{k}\right)}{\left(m_{\text {fuel }, O L}^{k}+\theta_{f}^{k}\right)+\left(\eta_{O L}^{k}+\theta_{\eta}^{k}\right) \frac{p_{i n t}^{k} V_{d i s}}{R T_{i n t}^{k}}}
\end{aligned}
$$

In order to include different available sensor information (the virtual trapped mass sensor, the EGR mass estimation from the orifice model, the intake pressure sensor, and the UEGO sensor at the exhaust), four outputs have been included, such as:

$$
\begin{aligned}
m_{c y l}^{k} & =\frac{1}{1-R G F^{k}}\left[\left(m_{f u e l, O L}^{k}+\theta_{f}^{k}\right)+\left(\eta_{O L}^{k}+\theta_{\eta}^{k}\right) \frac{p_{i n t}^{k} V_{d i s}}{R T_{i n t}^{k}}\right] \\
m_{E G R}^{k} & =m_{E G R}^{k} \\
p_{\text {int }}^{k} & =p_{i n t}^{k} \\
1 / \lambda^{k} & =1-\frac{F_{e x h}^{k}}{F_{\text {air }}}
\end{aligned}
$$

The system uses five inputs in order to run the models, namely the air mass flow given by the anemometer, the residual gas fraction obtained from (4), the intake temperature sensed by a thermocouple, and the volumetric efficiency and the fuel mass estimations given by open-loop models. The engine speed was used to convert the mass flow measurement from the MAF sensor and the EGR model to admitted air and EGR per stroke. 
A discrete form with one cycle step was chosen, following the state space

representation of the system:

$$
\begin{aligned}
x_{k+1} & =f\left(x_{k}, u_{k}\right)+w_{k} \\
y_{k} & =g\left(x_{k}, u_{k}\right)+v_{k}
\end{aligned}
$$

where $x$ are the states, modelled by $f\left(x_{k}, u_{k}\right)$ (Equations (13) to (19)), $y$ the outputs described by $g\left(x_{k}, u_{k}\right)$ (Equations (20) to (13)), $u$ the inputs, $w$ the associated noise to the states equation, and $v$ the noise associated to the outputs.

The KF of the state vector is defined by:

$$
\begin{aligned}
\hat{x}_{k \mid k-1} & =f\left(\hat{x}_{k-1}, u_{k}\right) \\
e_{k} & =y_{k}-g\left(\hat{x}_{k \mid k-1}, u_{k}\right) \\
\hat{x}_{k} & =\hat{x}_{k \mid k-1}+K_{k} e_{k}
\end{aligned}
$$

The KF is characterized for minimizing the expected estimation error by solving an iterative Riccati matrix equation and updating the value of the Kalman gain $(K)$. Following:

$$
\begin{aligned}
P_{k \mid k-1} & =\left(F_{k} P_{k-1} F_{k}^{T}+Q_{k}\right) \\
K_{k} & =P_{k \mid k-1} H_{k}^{T}\left(H_{k} P_{k \mid k-1} H_{k}^{T}+R_{k}\right)^{-1} \\
P_{k} & =\left(I-K_{k} H_{k}\right) P_{k \mid k-1}
\end{aligned}
$$

where $w$ and $v$ are modelled as a Gaussian distribution with zero mean and covariance matrices $Q_{k}$ and $R_{k}$, respectively, which are constant and diagonal. $F_{k}$ and $H_{k}$ are the linear state matrices representing Equations (24) and (25). As these equations are non-linear an extended Kalman filter (EKF) was used by linearising them, such as:

$$
\begin{aligned}
F_{k, i j} & =\left.\frac{\delta f_{i}}{\delta x_{j}}\right|_{x=\hat{x}_{k}} \\
H_{k, i j} & =\left.\frac{\delta g_{i}}{\delta x_{j}}\right|_{x=\hat{x}_{k}}
\end{aligned}
$$


The noise of each equation was maintained constant with the exception of the admitted EGR at the intake, which was set to 0 when the EGR valve is fully closed, i.e. EGR mass flow is certainly zero when the EGR valve is closed. A low noise is associated with the trapped mass given by the resonance method $(10 \mathrm{mg} / \mathrm{str})$, a higher value associated to the air mass flow given by the anemometer to cope with ageing effect $(100 \mathrm{mg} / \mathrm{str})$ and an even higher value to the EGR model because of the uncertainties at the model (1000 $\mathrm{mg} / \mathrm{str}$ ), i.e. effective flow area, EGR inlet temperature, etc. In this way the Kalman filter is capable of correcting the bias in the air mass flow anemometer when the EGR valve is closed, while harnesses the information provided by resonance to estimate the EGR in the rest of the conditions. The rest of the values are selected for a robust and fast operation of the filter by avoiding instabilities and permitting fast changes at the parameters. Table 2 collects all the noise values used in the Kalman filter.

Table 2

Noise suggested for the Kalman filter: the last column gives dimensonless value of the noise by using the maximum value obtained in an experimental test

\begin{tabular}{ccccc} 
Variable & Type & Equation & Value [unit] & Dimensionless [\%] \\
\hline$\theta_{\eta}$ & State & $(13)$ & $0.01[-]$ & 1.1 \\
$\theta_{\text {fuel }}$ & State & $(14)$ & $5[\mathrm{mg} / \mathrm{str}]$ & 10 \\
$\theta_{\text {air }}$ & State & $(15)$ & $100[\mathrm{mg} / \mathrm{str}]$ & 3.5 \\
$m_{E G R}$ & State & $(16)$ & $100[\mathrm{mg} / \mathrm{str}]$ & 8 \\
$p_{\text {int }}$ & State & $(17)$ & $100[\mathrm{mbar}]$ & 0.1 \\
$F_{\text {int }}$ & State & $(18)$ & $1[\%]$ & 4.7 \\
$F_{\text {exh }}$ & State & $(19)$ & $1[\%]$ & 7.1 \\
\hline$m_{\text {cyl }}$ & Output & $(20)$ & $10[\mathrm{mg} / \mathrm{str}]$ & 0.3 \\
$m_{E G R}$ & Output & $(21)$ & $120($ or 0$)[\mathrm{mg} / \mathrm{str}]$ & 10 \\
$p_{\text {int }}$ & Output & $(22)$ & $10[\mathrm{mbar}]$ & 0.01 \\
$1 / \lambda$ & Output & $(23)$ & $1[-]$ & 10
\end{tabular}

Figure 5 shows the output the Kalman filter, namely volumetric efficiency, trapped mass, air, and EGR, when three combination of noises (Noise A, Noise B, and Noise C) are used in the HP-EGR step performed at $1200 \mathrm{rpm}$ and $25 \%$ load. The measurement of the trapped mass provided by resonance, the value of the hot-film anemometer and the output of the EGR model have been also represented by a dashed line. Noise A is the output of the Kalman 
filter when the values collected in Table 2 are used, Noise B show the effect of increasing the noise of the trapped mass measurement above the EGR measurement noise, while Noise $\mathrm{C}$ show the effect of increasing the noise to Equation (15) and thus, facilitating the correction of the air mass flow.
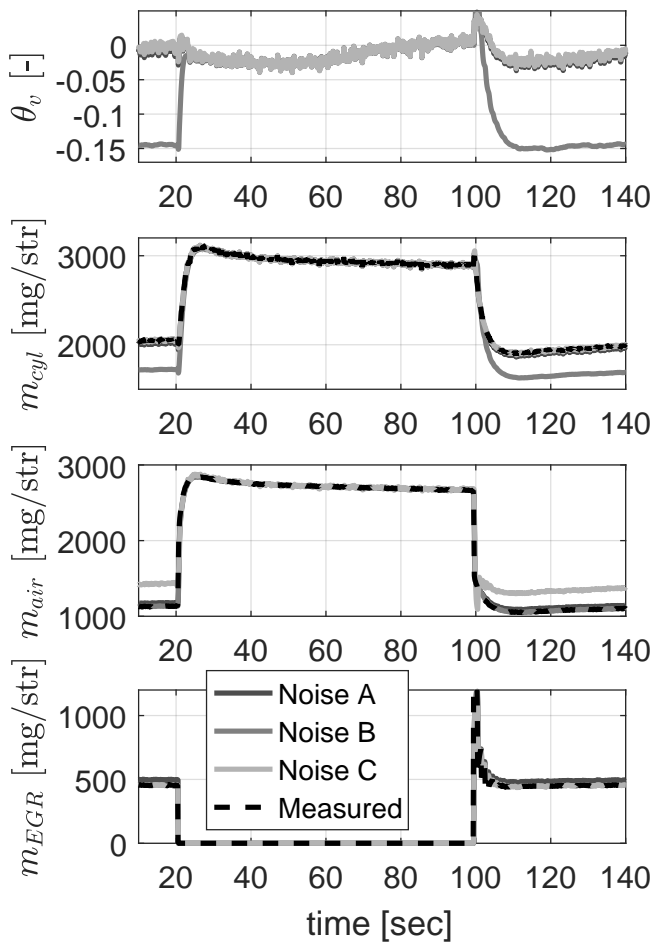

Fig. 5. Output of the Kalman filter (volumetric efficiency, trapped mass, air, and EGR) at the HP-EGR step at $1200 \mathrm{rpm}$ and $25 \%$ load

Note that the model of the EGR (calibrated from the Horiba) is probably giving a bad measurement, as the volumetric efficiency needs to be lowered bellow 0.8 to be consistent with the air mass flow and the EGR model. This is explained by incomplete mixing in HP-EGR loops at the gas analyser probe location and cylinder-to-cylinder dispersion, such as reported by [48, 49, 50]. In order to guarantee the robustness of the Kalman filter when bias in the EGR model are produced, the values used in Nose A were used for the rest of the tests. 


\section{Results and discussion}

Figure 7 shows the results of the first tests, where the VGT was controlled to ensure variations in the trapped mass at various engine speed conditions, such as shown previously in Figure 2. The top plot shows the output of RGF model, Eq. (4), the medium plot shows the result of the volumetric efficiency by using the anemometer, through:

$$
\eta_{v}=\frac{m_{i n t} p_{i n t} V_{d i s}}{R T_{i n t}}=\frac{m_{a i r} p_{i n t} V_{d i s}}{R T_{i n t}}
$$

and finally the bottom plot shows the trapped mass obtained from the resonance method and is compared with the result given by models and sensors, such as:

$$
m_{c y l}=\frac{m_{\text {int }}+m_{\text {fuel }}}{1-R G F}=\frac{m_{\text {air }}\left(1+\frac{1}{14.6 \lambda}\right)}{1-R G F}
$$
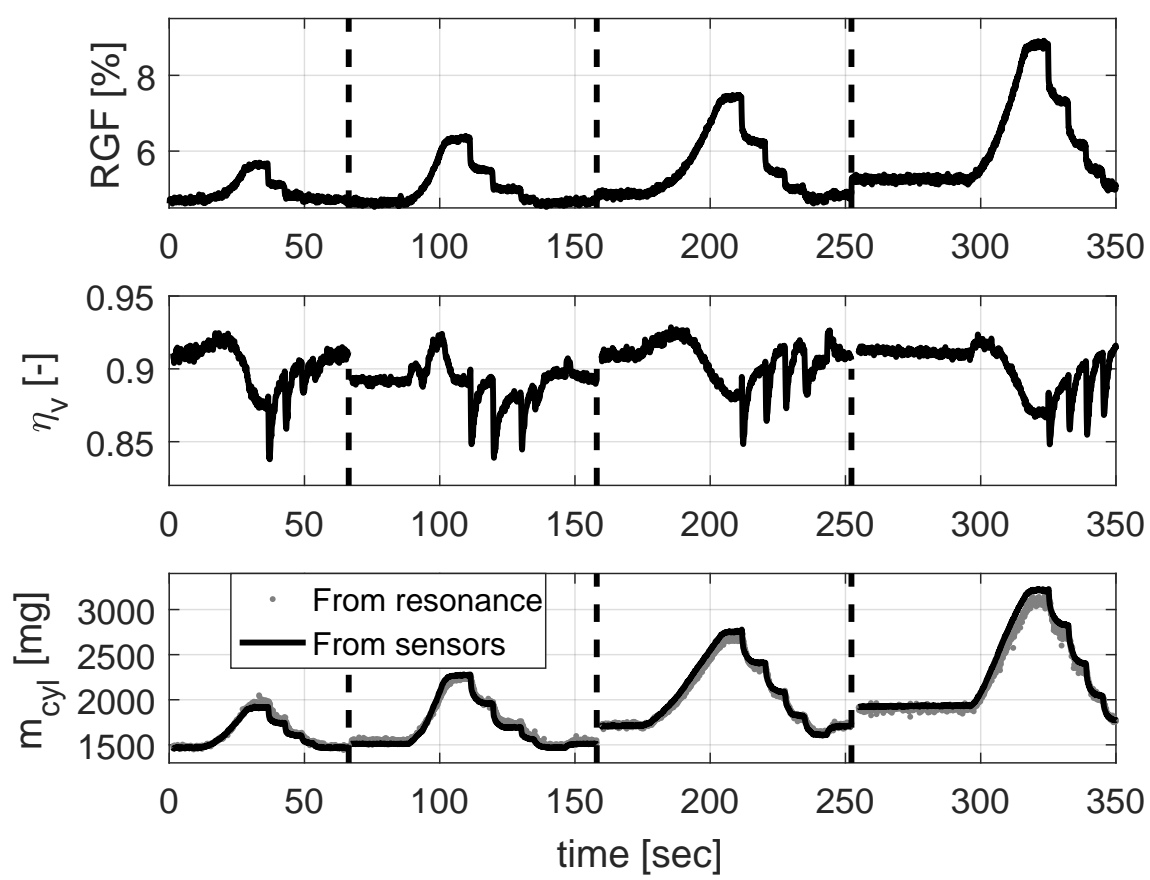

Fig. 6. Results of the calibration tests: RGF (top plot), volumetric efficiency (medium plot), and mass from resonance (bottom plot)

It must be noticed that the values of volumetric efficiency are only valid when slow variations of VGT are performed but when performing fast steps, different values are obtained. Furthermore, the output of the resonance method is consistent with the air mass flow anemometer, i.e. the mean absolute error is $19.05 \mathrm{mg}$ and the mean relative error $0.55 \%$, which is, indeed, a validation of the resonance methodology in steady conditions. 
Regarding the applicability of the Kalman filter for the transient estimation, Figure 7 shows the trapped mass obtained from the in-cylinder pressure resonance, the air mass flow sensed by the hot-film anemometer, and the intake mass obtained from the volumetric efficiency adaptation of the Kalman filter. It must be remembered that trapped mass considers the residual gasses and the injected fuel mass, while intake mass not, such as described in Eq. (35).

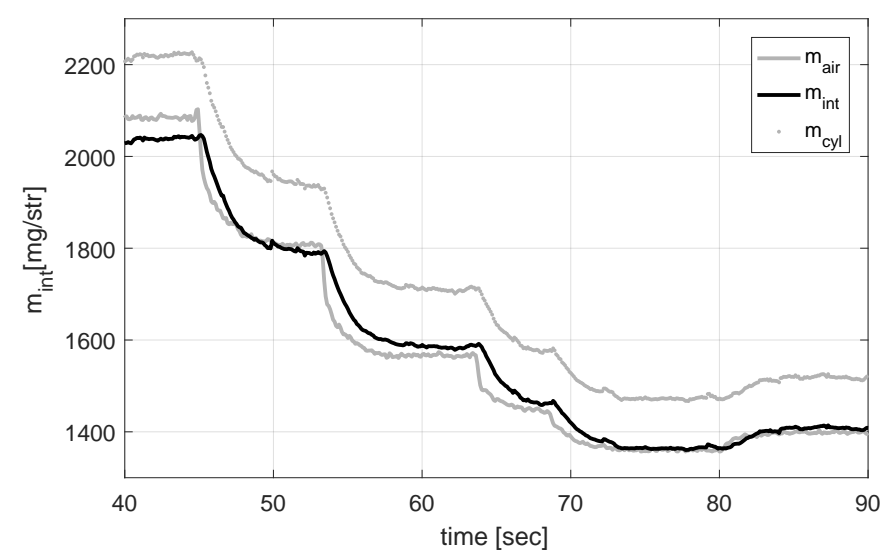

Fig. 7. Kalman filter and sensor ouputs for the transient VGT steps shown in at $1200 \mathrm{rpm}$

In this case, the volumetric efficiency was corrected up to a $3 \%$, while the bias at the air mass flow sensor reached a maximum of $40 \mathrm{mg} / \mathrm{str}$ (over 2080 $\mathrm{mg} / \mathrm{str}$ ) at the beginning of the test. Note that the Kalman filter is able to take into account the intake flow transient evolution, which is captured by the measurement of the trapped mass from resonance, and is consistent with the hot-film anemometer output ant the intake manifold dynamics.

Regarding the EGR estimation, Figure 8 shows the results of the LP and the HP EGR steps. The top plot compares the EGR mass flow obtained at the Kalman filter, with the measurement obtained from the gas analyser by $\mathrm{CO}_{2}$ balance, and with the output of the model described in Eq. (6). The steady values of effective flow area of the model have been fitted with the steady result of the gas analyser. The bottom plot compares the trapped mass obtained at the Kalman filter, with the measurement directly calculated from sensors, such as:

$$
m_{c y l}=\frac{m_{E G R}+m_{a i r}\left(1+\frac{1}{14.6 \lambda}\right)}{1-R G F}
$$



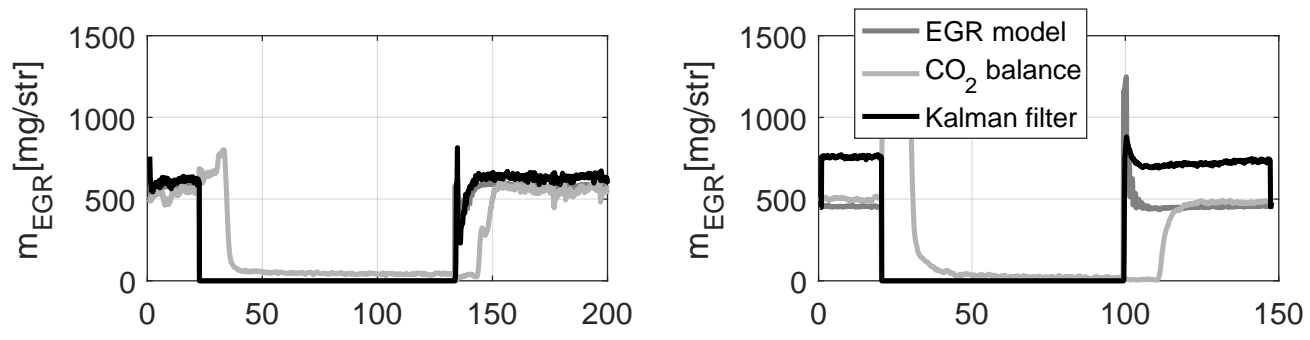

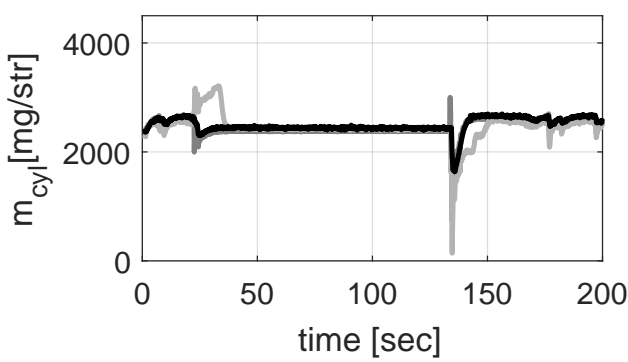

(a) LP-EGR step

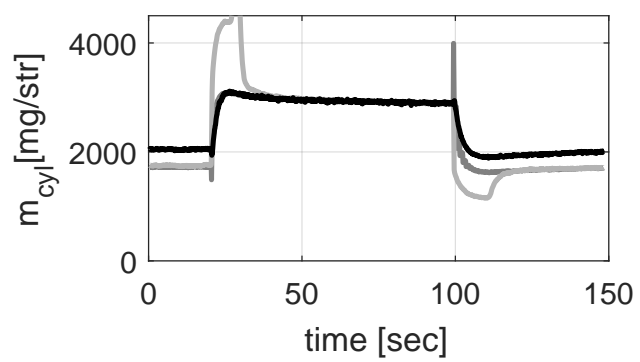

(b) HP-EGR step

Fig. 8. EGR and trapped mass at the LP and HP EGR steps at $1200 \mathrm{rpm}$ and $25 \%$ load

The offset and the erratic transient measurement at the gas analyser is caused by the different transport delay at the analysed lines (intake and exhaust). Regarding steady results, the differences obtained between the Kalman filter and the gas analyser when using LP-EGR loop are very small, but when using HP-EGR, a $33.3 \%$ of differences are found. Similar values were obtained for the steps performed at $75 \%$ load, i.e. small errors at LP-EGR loop but $170 \mathrm{mg}$ of differences over $500 \mathrm{mg}(34 \%)$ at the HP-EGR loop. As commented before, this is consistent with other researches on the topic.

The volumetric efficiency bias required for obtaining such results is shown in the top plot of Figure 9, while in the bottom plot the resulting oxygen concentration (at the intake and at the exhaust) is represented. The Kalman filter modifies the volumetric efficiency within a normal range $( \pm 0.05)$ for being consistent with sensor and models, while the output of the oxygen concentration can be used for control and diagnosis purposes.

\section{Conclusions}

A Kalman filter has been designed for integrating a new methodology of trapped mass estimation, which analyses the in-cylinder pressure resonance, with on-board sensors, namely lambda, air mass flow anemometer, and intake 

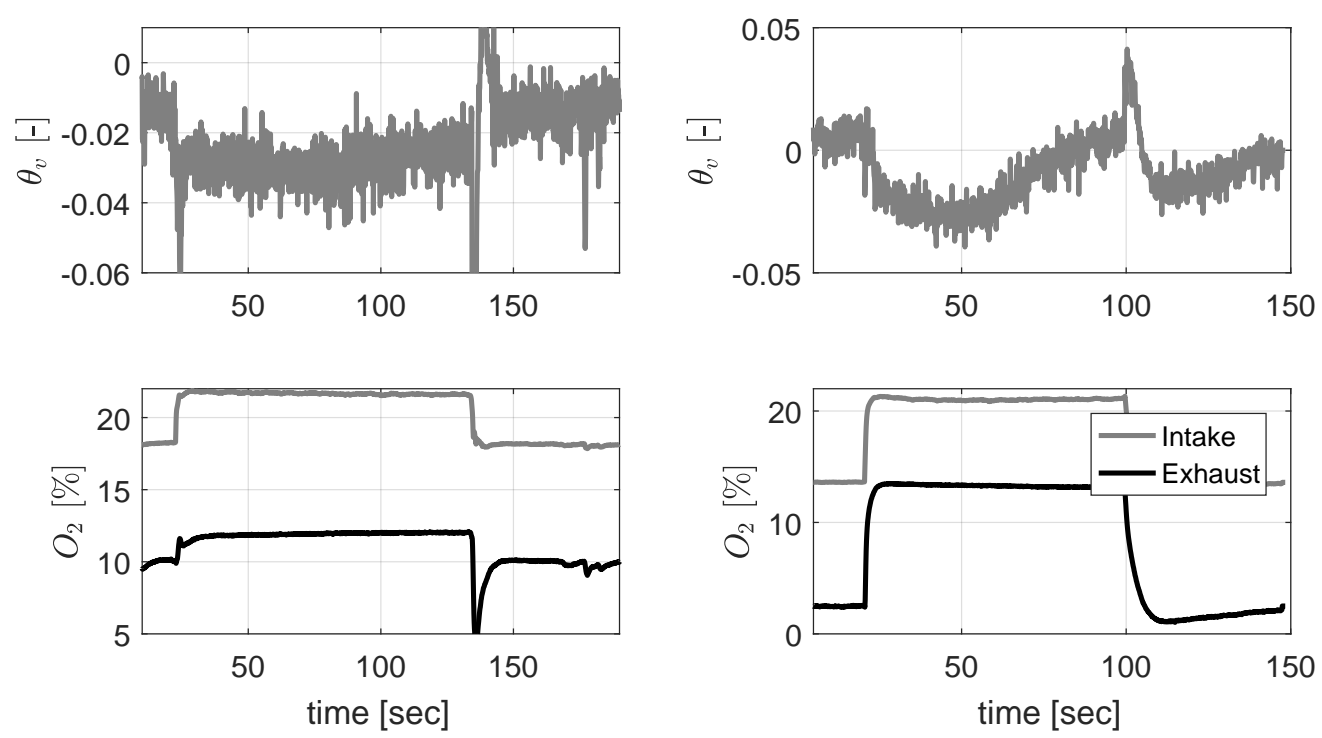

(a) LP-EGR step

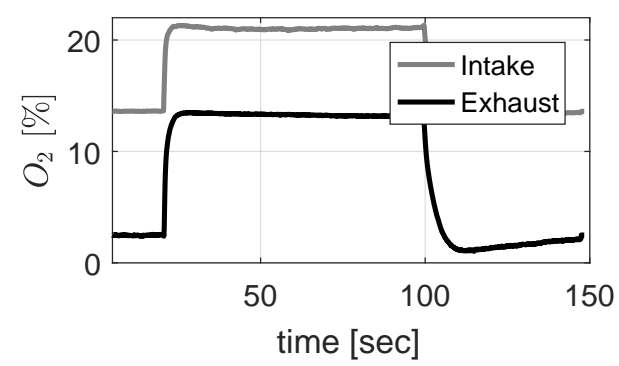

(b) HP-EGR step

Fig. 9. Bias at the volumetric efficiency and $\mathrm{O}_{2}$ concentrations at the LP and HP EGR steps at $1200 \mathrm{rpm}$ and $25 \%$ load

pressure and temperature sensors. The observer uses several models and sensors for independently consider each mass flow, ending up with an estimation of the trapped mass and the oxygen concentration at the intake and exhaust manifold.

Because of the additional measurement of the trapped mass, the Kalman filter is capable of correcting the air mass flow measurement given by the anemometer, which might suffer from bias when changing the operating conditions, when the EGR valve is closed. When the EGR valve is controlled to provide the combustion chamber with sufficient residual gases, the resonance method gives a valuable measurement for a precise estimation of the EGR, which is hard to measure, even in test benches, specially when HP-EGR loops are considered. Furthermore, the resonance method gives a direct measurement of the trapped mass at the cylinder, which is profited by the observer for considering the intake manifold dynamics.

A heavy-duty four stroke engine has been used for validation of the observer: steps in the VGT and in the EGR have been performed. Regarding the steady accuracy of the observer output, the estimated EGR mass is similar to that measured with a gas analyser, when only the LP-EGR loop is used and a good mixing and cylinder-to-cylinder distribution are achieved. When the HP-EGR loop is activated, the observer is capable of detecting an error on the EGR sensing procedure. The observer, which integrates the information from the 
transient response in the steps tested.

\section{References}

[1] B.A. Al-Himyari, A. Yasin, and H. Gitano. Review of air-fuel ratio pre-

[2] Y. Zhao, T. Shen, and X. Jiao. Air-fuel ratio transient control design for gasoline engines based on individual cylinder air charge estimation. SAE Technical Papers, 1, 2013.

[3] A. Yar and A. I. Bhatti. Control of air-to-fuel ratio of spark ignited engine using super twisting algorithm. In Proceedings - 2012 International Conference on Emerging Technologies, ICET 2012, pages 71-75, 2012.

[4] M. Yao, Q. Zhang, H. Liu, Z. . Zheng, P. Zhang, Z. Lin, T. Lin, and J. Shen. Diesel engine combustion control: Medium or heavy EGR? SAE Technical Papers, 2010.

[5] T. Lähde, T. Rönkkö, A. Virtanen, A. Solla, M. Kytö, C. Söderström, and J. Keskinen. Dependence between nonvolatile nucleation mode particle and soot number concentrations in an egr equipped heavy-duty diesel engine exhaust. Environmental Science and Technology, 44(8):3175-3180, 2010.

455 [6] A. J. Nicol, C. Such, and U. Sarnbratt. Investigation of fuel injection strategies on a low emission heavy-duty diesel engine with high egr rates. In Institution of Mechanical Engineers: Combustion Engines and Fuels Group - Internal Combustion Engines: Performance, Fuel Economy and Emissions, pages 173-183, 2008.

460 [7] H. Zhu, S. V. Bohac, K. Nakashima, L. M. Hagen, Z. Huang, and D. N. Assanis. Effect of fuel oxygen on the trade-offs between soot, NOx and combustion efficiency in premixed low-temperature diesel engine combustion. Fuel, 112:459-465, 2013.

[8] J. Thangaraja and C. Kannan. Effect of exhaust gas recirculation on advanced diesel combustion and alternate fuels - a review. Applied Energy, 180:169-184, 2016.

[9] T. Karthikeya Sharma, G. Amba Prasad Rao, and K. Madhu Murthy. Control of peak pressures of an HCCI engine under varying swirl and operating parameters. Frontiers in Energy, 10(3):337-346, 2016.

[10] F. Taglialatela, N. Cesario, and M. Lavorgna. Soft computing mass air flow estimator for a single-cylinder si engine. SAE Technical Papers, 2006.

[11] P. J. Buehler, M. A. Franchek, and I. Makki. Mass air flow sensor diagnostics for adaptive fueling control of internal combustion engines. In Proceedings of the American Control Conference, volume 3, pages 2064- 
[12] G. Brasseur. Robust automotive sensors. In Conference Record - IEEE Instrumentation and Measurement Technology Conference, volume 2, pages 1278-1283, 1997.

[13] D. A. Ziesmer, M. D. Chuey, and L. Hazelton. Frequency domain characterization of mass airflow sensors. SAE Technical Papers, 1993.

[14] X. Wang. Parameter determination of dynamic sensor model with particle swarm optimization technique. In 2009 International Conference on Measuring Technology and Mechatronics Automation, ICMTMA 2009, volume 1, pages 43-46, 2009.

[15] K. Xu, J. Zhang, X. Wang, Q. Teng, J. Tan, and Y. Zhang. Improvements of nonlinear dynamic modeling of hot-film MAF sensor. Sensors and Actuators, A: Physical, 147(1):34-40, 2008.

[16] J. Zhao and J. Wang. Engine mass airflow sensor fault detection via an adaptive oxygen fraction observer. In 2014 American Control Conference, pages 1517-1522. IEEE, 2014.

[17] G. Betta, D. Capriglione, A. Pietrosanto, and P. Sommella. ANN-based sensor fault accommodation techniques. In Diagnostics for Electric $\mathrm{Ma}$ chines, Power Electronics \&5 Drives (SDEMPED), 2011 IEEE International Symposium on, pages 517-524, 2011.

[18] Z. Liu and C. Wang. An LPV adaptive observer for updating a map applied to an MAF sensor in a diesel engine. Sensors, 15(10):2714227159, 2015.

[19] F. Payri, J. M. Luján, C. Guardiola, and G. Rizzoni. Injection diagnosis through common-rail pressure measurement. Proceedings of the Institution of Mechanical Engineers, Part D: Journal of Automobile Engineering, 220(3):347-357, 2006.

[20] V. Macián, J. M. Luján, C. Guardiola, and A. Perles. A comparison of different methods for fuel delivery unevenness detection in diesel engines. Mechanical Systems and Signal Processing, 20(8):2219-2231, 2006.

[21] A. E. Catania, A. Ferrari, M. Manno, and E. Spessa. Experimental investigation of dynamics effects on multiple-injection common rail system performance. Journal of Engineering for Gas Turbines and Power, 130(3), 2008.

[22] A. E. Catania, A. Ferrari, and E. Spessa. Numerical-experimental study and solutions to reduce the dwell-time threshold for fusion-free consecutive injections in a multijet solenoid-type cr system. Journal of Engineering for Gas Turbines and Power, 131(2), 2009.

[23] S. Regitz and N. Collings. Study of cycle-by-cycle air-to-fuel ratio determined from the exhaust gas composition and a novel fast response device based on a wide band lambda sensor. SAE Technical Papers, 2008.

[24] S. Klett, M. Piesche, S. Heinzelmann, H. Weyl, H. . Wiedenmann, U. Schneider, L. Diehl, and H. Neumann. Numerical and experimental analysis of the momentum and heat transfer in exhaust gas sensors. SAE Technical Papers, 2005.

[25] N. Kato, N. Kokune, B. Lemire, and T. Walde. Long term stable nox 
sensor with integrated in-connector control electronics. SAE Technical Papers, 1999.

[26] N. Kato, K. Nakagaki, and N. Ina. Thick film $\mathrm{ZrO}_{2} \mathrm{NOx}$ sensor. $S A E$ Technical Papers, 1996.

${ }_{525}$ [27] Y. Nakanouchi, H. Kurosawa, M. Hasei, Y. Yan, and A. Kunimoto. New type of nox sensors for automobiles. SAE Technical Papers, 1996.

[28] A. Schilling. Model-Based Detection and Isolation of Faults in the Air and Fuel Paths of Common-rail DI Diesel Engines Equipped with a Lambda and a Nitrogen Oxides Sensor. PhD thesis, ETH Zurich, 2008.

[29] U. Asad and M. Zheng. Exhaust gas recirculation for advanced diesel combustion cycles. Applied Energy, 123:242-252, 2014.

[30] U. Asad. Advanced diagnostics, control and testing of diesel low temperature combustion. PhD thesis, University of Windsor, 2009.

[31] J.B. Heywood. Internal Combustion engine fundamentals. McGraw-Hill, New York, 1988.

[32] L. Guzzella and C. Onder. Introduction to modeling and control of internal combustion engine systems. Springer, Berlin Heidelberg, 2010.

[33] Z. Wang, Q. Zhu, and R. Prucka. A review of spark-ignition engine air charge estimation methods. SAE Technical Papers, 2016.

[34] Z. Peng and M. Jia. An investigation and evaluation of variable-valvetiming and variable-valve-actuation strategies in a diesel homogeneous charge compression ignition engine using three-dimensional computational fluid dynamics. Proceedings of the Institution of Mechanical Engineers, Part D: Journal of Automobile Engineering, 222(6):1047-1064, 2008.

[35] M. Jankovic and S. W. Magner. Cylinder air-charge estimation for advanced intake valve operation in variable cam timing engines. JSAE review, 22(4):445-452, 2001.

[36] B. Kolewe, A. Haghani, R. Beckmann, R. Noack, and T. Jeinsch. Datadriven estimation of air mass using gaussian mixture regression. In IEEE International Symposium on Industrial Electronics, pages 24332438, 2014.

[37] G. W. Malaczynski, M. Mueller, J. Pfeiffer, D. Cabush, and K. Hoyer. Replacing volumetric efficiency calibration look-up tables with artificial neural network-based algorithm for variable valve actuation. SAE Technical Papers, 2010.

[38] B. Wu, Z. Filipi, D. Assanis, D. M. Kramer, G. L. Ohl, M. J. Prucka, and E. Divalentin. Using artificial neural networks for representing the air flow rate through a 2.4 liter VVT engine. SAE Technical Papers, 2004.

[39] J. El Hadef, G. Colin, V. Talon, and Y. Chamaillard. Neural model for real-time engine volumetric efficiency estimation. SAE Technical Papers, 6, 2013.

[40] R. C. Turin, R. Zhang, and M. Chang. Volumetric efficiency model for variable cam-phasing and variable valve lift applications. SAE Technical Papers, 2008. 
[41] L. Kocher, E. Koeberlein, D. G. Van Alstine, K. Stricker, and G. Shaver. Physically based volumetric efficiency model for diesel engines utilizing variable intake valve actuation. International Journal of Engine Research, 13(2):169-184, 2012.

[42] A. Chevalier, M. Müller, and E. Hendricks. On the validity of mean value engine models during transient operation. SAE Technical Papers, 2000.

[43] L. A. Smith, T. Fickenscher, and R. P. Osborne. Engine breathing steady speed volumetric efficiency and its validity under transient engine operation. SAE Technical Papers, 1999.

[44] J.D. Benson and R.F. Stebar. Effects of charge dilution on nitric oxide emission from a single-cylinder engine. SAE Technical Paper, 1971.

[45] R.C. Yu and S.M. Shahed. Effects of injection timing and exhaust gas recirculation on emissions from a di diesel engine. SAE Preprints, 811234, 1981.

[46] D. A. Pierpont, D. T. Montgomery, and R. D. Reitz. Reducing particulate and nox using multiple injections and egr in a D.I. diesel. SAE Technical Papers, 1995.

[47] U. Asad, J. Tjong, and M. Zheng. Exhaust gas recirculation - zero dimensional modelling and characterization for transient diesel combustion control. Energy Conversion and Management, 86:309-324, 2014.

[48] J. M. Luján, H. Climent, B. Pla, M. E. Rivas-Perea, N. François, J. Borges-Alejo, and Z. Soukeur. Exhaust gas recirculation dispersion analysis using in-cylinder pressure measurements in automotive diesel engines. Applied Thermal Engineering, 89:459-468, 2015.

[49] J. M. Luján, J. Galindo, J. R. Serrano, and B. Pla. A methodology to identify the intake charge cylinder-to-cylinder distribution in turbocharged direct injection diesel engines. Measurement Science and Technology, 19(6), 2008.

[50] F. Payri, J. Luján, H. Climent, and B. Pla. Effects of the intake charge distribution in hsdi engines. SAE Technical Papers, 2010.

[51] J. Zhao and J. Wang. Adaptive observer for joint estimation of oxygen fractions and blend level in biodiesel fueled engines. IEEE Transactions on Control Systems Technology, 23(1):80-90, 2015.

[52] I. Kolmanovsky and I. Siverguina. Adaptive identification schemes in presence of bounded disturbances: An automotive case study. In Proceedings of the IEEE Conference on Decision and Control, volume 1, pages 508-513, 2001.

[53] I. Kolmanovsky, I. Sivergina, and J. Sun. Simultaneous input and parameter estimation with input observers and set-membership parameter bounding: Theory and an automotive application. International Journal of Adaptive Control and Signal Processing, 20(5):225-246, 2006.

[54] C. Guardiola, B. Pla, D. Blanco-Rodriguez, and P. Bares. Cycle by cycle trapped mass estimation for diagnosis and control. SAE Int. J. Engines, $7(3), 2014$.

${ }_{610}$ [55] J. M. Luján, C. Guardiola, B. Pla, and P. Bares. Estimation of trapped 
mass by in-cylinder pressure resonance in HCCI engines. Mechanical Systems and Signal Processing, 66-67:862-874, 2015.

[56] A. Broatch, C. Guardiola, B. Pla, and P. Bares. A direct transform for determining the trapped mass on an internal combustion engine based on the in-cylinder pressure resonance phenomenon. Mechanical Systems and Signal Processing, 62:480-489, 2015.

[57] C. Guardiola, V. Triantopoulos, P. Bares, S. Bohac, and A. Stefanopoulou. Simultaneous estimation of intake and residual mass using in-cylinder pressure in an engine with negative valve overlap. IFACPapersOnLine, 49(11):461-468, 2016.

[58] C. Guardiola, J. Martín, J. Pla, and P. Bares. Cycle by cycle NOx model for diesel engine control. Applied Thermal Engineering, 110:10111020, 2017.

[59] M. Kao and J.J. Moskwa. Turbocharged diesel engine modeling for nonlinear engine control and state estimation. Journal of Dynamic Systems, Measurement and Control, Transactions of the ASME, 117(1):2030, 1995.

[60] E. Hendricks, A. Chevalier, M. Jensen, S. C. Sorenson, D. Trumpy, and J. Asik. Modelling of the intake manifold filling dynamics. SAE Technical Papers, 1996.

[61] M. Fons, M. Muller, A. Chevalier, C. Vigild, E. Hendricks, and S. C. Sorenson. Mean value engine modelling of an si engine with egr. $S A E$ Technical Papers, 1999.

[62] T. Leroy, J. Chauvin, G. Le Solliec, and G. Corde. Air path estimation for a turbocharged si engine with variable valve timing. In Proceedings of the American Control Conference, pages 5088-5093, 2007.

[63] Per Andersson. Intake air dynamics on a turbocharged SI-engine with wastegate. Department of Electrical Engineering, Linköping University, 2002.

[64] E. Hendricks, T. Vesterholm, and S. C. Sorenson. Nonlinear, closed loop, si engine control observers. SAE Technical Papers, 1992.

[65] C. Liu. Simultaneous unknown state and input estimation with application to virtual air charge and egr sensors for automotive engines. In $A S M E$ 2010 Dynamic Systems and Control Conference, DSCC2010, volume 1, pages 727-734, 2010.

[66] I. Kolmanovsky, J. Sun, M. Druzhinina, and M. van Nieuwstadt. Charge control for direct injection spark ignition engines with egr. In Proceedings of the American Control Conference, volume 1, pages 34-38, 2000.

[67] J. Chauvin, G. Corde, N. Petit, and P. Rouchon. Motion planning for experimental airpath control of a diesel homogeneous charge-compression ignition engine. Control Engineering Practice, 16(9):1081-1091, 2008.

[68] F. Castillo, E. Witrant, V. Talon, and L. Dugard. Simultaneous air fraction and low-pressure EGR mass flow rate estimation for diesel engines. In IFAC Proceedings Volumes (IFAC-PapersOnline), pages 731-736, 2013.

[69] Rudolph Emil Kalman. A new approach to linear filtering and prediction 
problems. Journal of basic Engineering, 82(1):35-45, 1960.

[70] D. Simon. Optimal State Estimation: Kalman, H Infinity, and Nonlinear Approaches. John Willey \& Sons, 2006.

[71] Osvaldo Barbarisi, G Alessandro, and G Luigi. An extended Kalman observer for the in-cylinder air mass flow estimation. In Proceedings of MECA02 International Workshop on Diagnostics in Automotive Engines and Vehicles, Oct., Fisciano SA, pages 1-14, 2002.

[72] A. Dutka, H. Javaherian, and M. J. Grimble. State-dependent Kalman filters for robust engine control. In Proceedings of the American Control 665 Conference, volume 2006, pages 1185-1190, 2006.

[73] T. Polóni, B. Rohaĺ-Ilkiv, and T. Arne Johansen. Mass flow estimation with model bias correction for a turbocharged diesel engine. Control Engineering Practice, 23(1):22-31, 2014.

[74] H. J. Yun and W. Mirsky. Schlieren-streak measurements of instantaneous exhaust gas velocities from a spark-ignition engine. SAE Technical Papers, 1974.

[75] R. Kiwan, A. G. Stefanopoulou, J. Martz, G. Surnilla, I. Ali, and D. Joseph Styles. Effects of differential pressure measurement characteristics on low pressure-egr estimation error in si-engines. IFAC$675 \quad$ PapersOnLine, 49(11):722-729, 2016.

[76] R. Kiwan, A. Stefanopoulou, J. Martz, G. Surnilla, I. Ali, and D. Styles. Effects of differential pressure sensor gauge-lines and measurement accuracy on low pressure egr estimation error in si engines. SAE Technical Papers, 2017. 